\title{
GIS and Gravity Model-Based Accessibility Measure for Delhi Metro
}

\author{
Deepika Bhatt ${ }^{1} \cdot$ Minal $^{2}$ (1)
}

Received: 10 March 2021 / Accepted: 28 November 2021 / Published online: 4 January 2022

(C) Shiraz University 2021

\begin{abstract}
Metro is a rapid transit mode that helps in fast and efficient movement of the public. To make metro journey more convenient and attractive, from origin to destination, accessibility of metro must be good. In this study, tri-level analysis is carried out for the study area of Delhi. Traffic congestion and environmental condition of Delhi are degrading continuously, and to improve the situation, a sustainable Multi Modal Transport System (MMTS) with high accessibility must be explored. In this paper, policy to improve zone to zone metro accessibility for work purpose is discussed and the relation between multimodal transport system with accessibility is studied using GIS (ArcGIS), macrosimulation software (VISUM) and gravity model. It was observed that by the addition and extension of metro lines, transport accessibility is greatly improved. This study shows that percentage of zones in Delhi with higher accessibility level could increase from 5 to $13.88 \%$ with the implementation of phase IV of metro. In addition, the implementation of phase IV metro could reduce the average travel time between zones and metro stations. It will also reduce the travel time between metro stations substantially (for the zones covered in this study the average travel time is reduced by $23.63 \%$ and for the station covered in this study the average travel time is reduced by $17.73 \%$ ). Further, it was found that 'out vehicle travel time' (OVTT) is having a major impact on the accessibility of metro. Lastly, it was concluded that with the higher level of metro accessibility, people will prefer the multimodal transport system with metro as the main mode. Travel time isochrones for public and private trips for the estimated MMTS model are also presented in this paper to depict the changes in accessibility for different scenarios. This will further help in improving private transport accessibility by reducing congestion on roads. Thus, planning for transport accessibility helps in developing the city in a sustainable manner in the future.
\end{abstract}

Keywords Accessiblity $\cdot$ Metro $\cdot$ Multimodal transport system $\cdot$ Isochrones $\cdot$ Macrosimulation $\cdot$ GIS

\section{Introduction}

Transport system helps the commuters to reach the desired location for different purposes. People generally prefer their private travel mode due to the advantage of it being more convenient, comfortable, safer, and faster compared to public transport. To make commuters shift from private vehicle to public transport (bus, metro, etc.), it is required to improve the connectivity of the mass transit system. According to PTEG (PTEG 2010), connectivity for work, education,

\section{Minal}

minal.crri@nic.in

1 Transportation Systems Engineering, National Institute of Technology Karnataka, Surathkal 575025, India

2 Transportation Planning and Environmental Division, CSIR- Central Road Research Institute, New Delhi 110025, India business, etc. through public transport depends upon four main factors. The first factor is the availability of public transport that is public transport should be available in nearby place for a commuter. Second comes the accessibility that defines the measure of ease for reaching the destination (Farber and Fu 2017). The third is the affordability, i.e. fare system of public transport, and the last one is the acceptability of public transport over private transport.

Even though it is difficult to provide public transport services in very close vicinity, the effort can be made to make it more reachable by planning for the higher level of accessibility. Especially in the case of metro, it is required to provide the services which make metro more accessible for the public. Since the congestion and environment condition of Delhi are worsening, thus it is required to promote the metro over private transport for the sustainable development of the transport system. It is required to improve the 
services to access the metro and reach the destination with less travel time.

According to Hansen (1959), accessibility is defined as the potential of opportunities for interaction. Accessibility is an assessment to check if the area is highly accessible w.r.t. time, cost and effort. If reaching the desirable destination requires more time, cost and effort, the area is said to have low accessibility. Accessibility depends upon factors like the quality of transport system such as travel time, travel cost and the land use pattern (Handy and Niemeier 1997). Economic growth is directly related to the accessibility as time saved in travel will be invested in the growth of an individual and in turn will help in increasing the growth rate of the country. To realise the full potential of improved transport accessibility for every individual, the method of transportation planning should be modified.

Planning should be done in a way, so as to allow one to reach from origin to destination with greater ease and mobility. Three ways in which accessibility can be improved are: by increasing (a) mobility, (b) connectivity and (c) proximity. The major issue is how to make facilities accessible in a sustainable manner. Most of the time, transport planning is done according to future forecasting and estimating the congestion level and does not take "accessibility" into consideration. This planning method has its disadvantages as it recommends expanding the road-network to decrease congestion and accommodate more vehicle traffic. Instead of only focusing on the vehicle traffic, accessibility-based planning takes into account the different public-transit modes as well as non-motorised modes in the planning process. With the rapid increase in demand, it is imperative to shift our transport planning approach, from planning for mobility to planning for accessibility (Straatemeier 2008). An accessible transport system also boosts the policy for equal access of disabled (Department for Transport 2018) and other vulnerable groups.

According to Chen et al. (2011), accessibility is directly related to ridership which in turn depends upon external and internal factors affecting public transit. Some of these exogenous and endogenous factors are employment, population, vehicle ownership, urban density, economic condition, reliability of service, frequency, comfort, fare, safety, etc. By considering these different parameters, many studies have been carried out. Accessibility measures were developed with different needs-based on time, cost, gender, vulnerable group, etc. by using different models. Gravity modelbased Hansen equation is one of the widely used and readily understood method for estimating transport accessibility (Bocarejo and Oviedo 2012). Researchers have used Hansen equation in different ways according to their viewpoint for studying accessibility by considering the different factors.

Delhi traffic is at saturation level (Minal and RaviSekhar 2016). One of the most effective way to reduce traffic on roads is by encouraging people to shift towards public transport and use a multimodal transport system (MMTS). This can be realised by providing a lucrative public transit facility to the commuters. Lack of proper accessibility to public transport is the main reason behind the reluctance to use public transit. For a throbbing transit oriented development of urban spaces, public transport accessibility must be inclusive in the planning process. It will lead to commuters conveniently, safely and comfortably changing the modes in their journey and thus helps in shifting public towards MMTS.

This study is carried out in the National capital of India, Delhi for measuring the metro accessibility. With the increasing traffic congestion and rush to further widen the roads, the most lucrative solution is to attract commuters from private modes to public transit like metro and boost MMTS. Metro system plays a major role in MMTS. Metro is a highly sustainable mode with the efficiency to transfer higher number of passengers with higher travel time reliability with less greenhouse gas emissions (DMRC 2015, 2016). It was observed that currently metro ridership is reduced by $8 \%$ from 2017 to 2018 (DMRC 2018) and facing the problem of lower ridership (Roy and Shah 2018). One of the reasons for lower ridership of Delhi metro is poor accessibility to reach metro stations. For e.g. the location of bus stops are not well integrated with metro stations entry and exit gates. The parking lots provided at metro stations should be planned strategically so as to boost 'park and ride' trips. Thus, this study investigates the accessibility of metro for the propagation of public transit and MMTS. The study was performed in three stages. Firstly, zone to zone metro accessibility is analysed for work purpose using macrosimulation software VISUM, Gravity model and ArcGIS using five parameters: journey time, journey distance, direct distance, out vehicle travel time and impedance. In the second stage, policy for accessibility is studied. In the last stage, the relationship between accessibility and MMTS is explored. These three stages of the study are carried out to make the policy for accessibility of metro which will help in reducing the share of private transport on roads.

In this research, the main objective is to compare the different parameters of accessibility and to find the most influencing parameter which can be easily understood and implemented by the planners. Further, a policy for improving metro accessibility for establishing MMTS in a metropolitant city of a developing country is also explored and discussed. This paper proceeds with a literature review and description of the study area, data collection method and study parameters. Further, the results from the analysis are discussed and policy simulation for MMTS system is evaluated. 


\section{Literature Review}

Various studies have been done in transport accessibility by considering different factors such as trip length, trip rate, land use, trip purpose, group-based, and socioeconomic factor. Accessibility can be measured in different ways depending upon the availability of data and requirement (Black and Conroy (1977), Kwan (1998), Yigitcanlar et al. (2007), Langford et al. (2012), Ford et al. (2015), etc.). It can be measured using a network that is number of links and nodes (Shimbel 1953), by considering the mode of transport and land use (Hansen 1959). Another way of measuring accessibility is based on the number of trips and travel cost (Savigear 1967). There are many other ways to measure accessibility, some of the measures of accessibility and factors which affect the accessibility are discussed in this section.

Hansen (1959) introduced the gravity-based approach to find the zone accessibility by summing up the opportunity available in each zone with the difficulty in reaching the zone by different modes. Generalised equation is given as Eq. (1)

$A_{i j m}=\sum_{j} B_{j} f\left(C_{i j}\right)$

where $A_{i j m}$ is accessibility of zone $i$ to zone $j$ for the purpose using mode $m . B_{j}$ is the attractiveness of zone $j$ for a given purpose. $f\left(C_{i j}\right)$ is the function to represent the travel cost from zone $i$ to $j$.

Similar to Hansen, many researchers have given different approaches to find the accessibility by considering different parameters for the function ' $f$ ', that is by considering different parameters as utility function (Wachs and Kumagai 1973; Frost and Spence 1995). Dalvin and Martin (1976) analysed the sensitivity between zone to zone accessibility using Hansen accessibility measure for private vehicle users. The different attractiveness parameter used were as follows: total employment, retail employment, household and population. The study concluded that accessibility parameter is highly sensitive to the choice of attractor variable. Al-Sahili and Aboul-Ella (1992) used descriptive measure rather than quantitative analysis to examine the zone accessibility for the public facility for a location by considering circular buffer zones of maximum walking distance around each facility. Through the study, they have shown that accessibility can be measured by using simple technique instead of using a complex one.

O'Sullivan et al. (2000) developed an effective set of desktop GIS tool with which isochrones map for accessibility analysis of public transport can be produced. Chang and Lee (2008) have done accessibility analysis of high speed rail by expanding Hansen method to GIS-based mapping audit along with ANOVA. This study was done to plan the priority that has to be given for the development of the area to increase the ridership for the high speed rail. According to Curtis (2008) for sustainable accessibility, the key principle is to integrate land use with transport along with inclusion of population and employment for the location of the region. Straatemeier (2008) pointed out the limitations of traditional transport planning and depicted how planning for accessibility is more advantageous than planning for mobility.

Prasertsubpakij and Nitivattananon (2012) studied metro accessibility for different users to develop multidimensional assessment of metro accessibility. It was suggested to balance the access for different groups, provide cost efficient feeders, safe access for individuals, and proper connectivity to metro. This will help the public to prefer public transport safely and comfortably. Bocarejo and Oviedo (2012) used characteristics of time and income spent for accessing work as input in function ' $f$ ' to measure real accessibility by using Hansen equation. Kumar, et al. (2013) have done study of multimodal transport system performance by considering travel time ratio, level of service, interconnectivity ratio, passenger waiting index, running index as parameters for analysing performance. They concluded that multimodal transport system is attractive when the access and egress distance is not large. Access and egress travel time can be reduced by providing proper access and egress facilities as parking facilities, feeder modes, pedestrian walking environment, cycle tracks, etc. Liu et al. (2018) proposed a model to see the station level ridership growth with expansion of rail network. According to the research, expansion in rail network not only helps in improving accessibility but also motivates the surroundings for the development which will increase the ridership. Xia et al. (2018) measured accessibility by estimating travel cost and related potential population flow using Gravity-Radiation model for population flow estimation, and Google Maps API for travel costs. The new estimated potential traveling population (EPTP) weighted travel costs showed strong correlation with the resident population.

Bivina et al. (2019) studied the accessibility of metro for pedestrian; as a result, it was found that walk accessibility to metro station is highly affected by safety and security, and mobility and infrastructure. Yang et al. (2019) focus on evaluating access to public transport service at stations, considering walking time to stations and waiting time for services at stations using Degree Centrality and Gravity Model in Wuhan. By modeling public transport operation, configuration and surroundings of stations, a comprehensive public transport service accessibility index (CPTAI) is formulated to quantify accessibility and shows significant statistical association with trips by public transport. Düring et al. (2019) developed a toolbox for spatial accessibility analysis adapted for datapoor environments and through three different case studies 
demonstrated the positive effect of improved accessibility on mobility patterns for multimodal transport, access to jobs and pedestrian frequency potentials.

Raju et al. (2020) carried out an accessibility analysis for healthcare centres using gravity model and geospatial techniques in Tiruchirappalli city. The study calculated spatial accessibility index using Floating Catchment Area, emergency factors travel time and travel impedance function. The study concluded that majority of hospitals are located near to the city centre and the periphery of the city shows very low spatial access to healthcare facilities. Wang et al. (2020) investigated the Accessibility and Gravity Model linkage to Regional Traffic and Economy for Hengyang, China, to realise different patterns of connections between districts of the study area.

Li et al. (2021) examined the time-varying accessibility to senior centres by public transit in Philadelphia and found that accessibility to senior centres declines from the downtown to the suburbs. It was also observed that neighbourhoods with higher shares of older adults tend to have lower accessibility to senior centres. The study suggested measures for transit authorities to better accommodate the diverse travel needs of older adults.

From the literature review, it is clear that many researchers have used Hansen equation for accessibility analysis by considering different parameters. Chang and Lee (2008) have used reduced form of Hansen equation by omitting the attraction factor. However, Dalvin and Martin (1976) have used Hansen equation for analysis of private transport by considering different attraction factors. On the other hand, Bocarejo and Oviedo (2012) used time and income both as the utility function in Hansen equation.

This research is based on relationship between metro system-based MMTS and accessibility. To measure the accessibility of the metro, different utility function based on time has been used in the analysis to get the most influential parameter. This study explores the effect of different measurement parameters like journey time, journey distance, direct distance, out vehicle travel time and impedance on the measure of accessibility for Delhi metro system. Further, the study explores how accessibility approach of transport planning can help in boosting MMTS and thus lead the way to sustainable transportation of the Delhi. To develop a transport model for accessibility measure and the policy that can be applied in developing city like Delhi in efficient manner has been explored.

\section{Study Area and Data Collection}

In this study, Delhi, the national capital of India, has been considered as the study area for the accessibility analysis of metro rail. For this study, primary data are taken from the Household survey which was conducted by Central Road Research Institute, New Delhi. The dataset consists of household information, socioeconomic data, trip information, and vehicle information. The secondary data consist of bus routes, headway information, metro routes, schedule of metro train and frequency. The information was collected from Delhi Transport Corporation (DTC) and Delhi Metro Rail Corporation (DMRC) site for Bus and Metro, respectively. The total study area was divided into pockets with 360 internal zones and 8 external zones and around 5100 samples were obtained. South Delhi region contains major commercial centres, educational institutions, markets and residential colonies and so approximately 3100 samples were collected from this region. The remaining 2000 samples were collected from North, East and West Delhi region. Figures 1 and 2 depict the Delhi metro phase II which was completed in 2011 and metro phase III (which is currently underway), respectively. Phase III of Delhi Metro was expected to be completed by the end of 2020 but construction was delayed due to the COVID-19 pandemic. Delhi Metro is one of the most disable-friendly mode in India. All the stations have ramps from the street and lifts have lower level of control panel for the accessibility of disabled people. Further, Delhi metro has all the facilities like a separate coach for women, reserved seats for the vulnerable groups, to make the metro accessible for women, senior citizen and other vulnerable group of people for their safe and convenient journey.

\subsection{Study Parameters}

In this study, primary data are used to develop the travel demand four stage model. The output from four stage model is further used to measure accessibility. Since our study is based on metro accessibility, thus we have extracted the metro skim matrix based on five internal factors. First, journey time (JRT) is the time between the departure from origin to arrival to the destination zone. The second parameter is journey distance (JRD), the distance covered between origin and destination zone. Third, direct distance (DID) is the direct distance between origin and destination. Fourth, out vehicle travel time (OVTT) includes the access time, egress time and transfer waiting time. Last one impedance consists of travel distance and travel time. These factors are related to convenience and comfort by public transport thus considered as internal factors. Further employment data of different zones were considered as attraction factor for the accessibility analysis. 
Fig. 1 Delhi Metro phase II

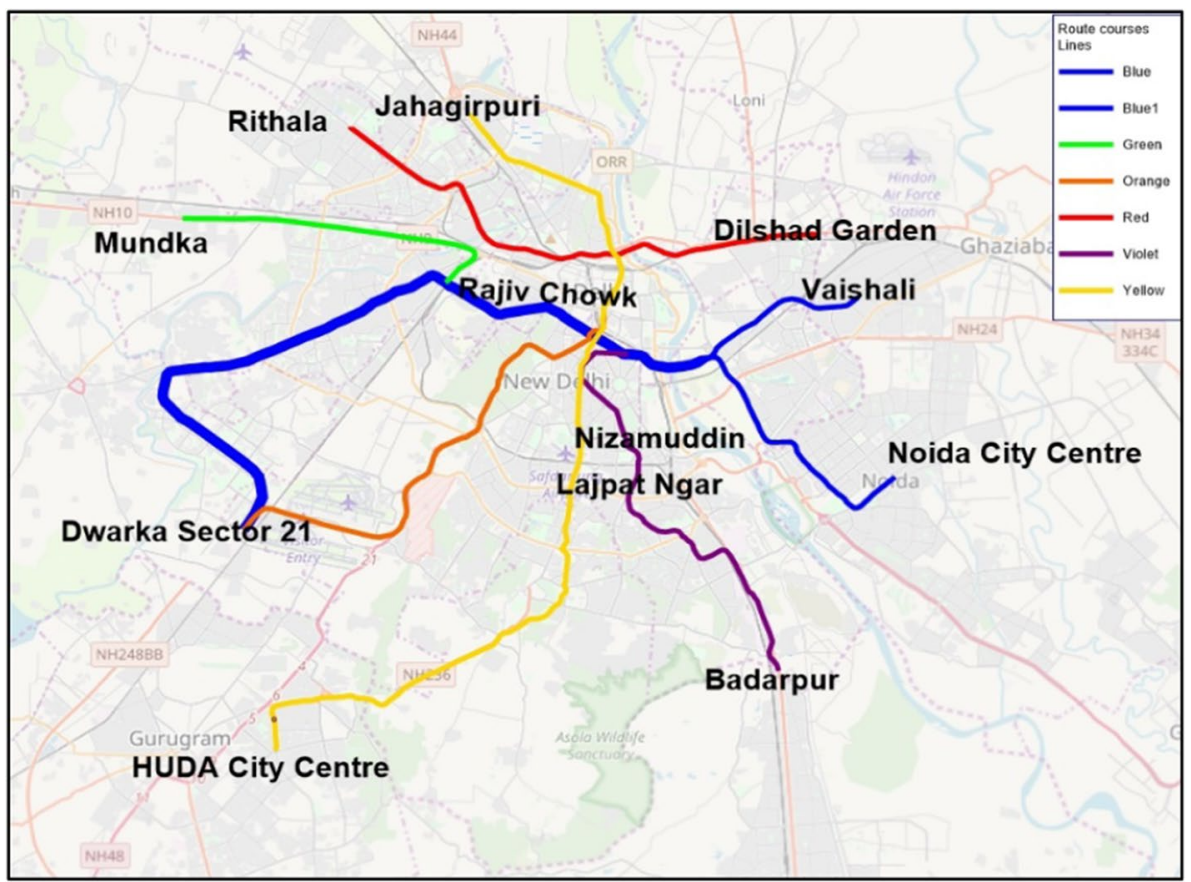

Fig. 2 Delhi Metro phase III

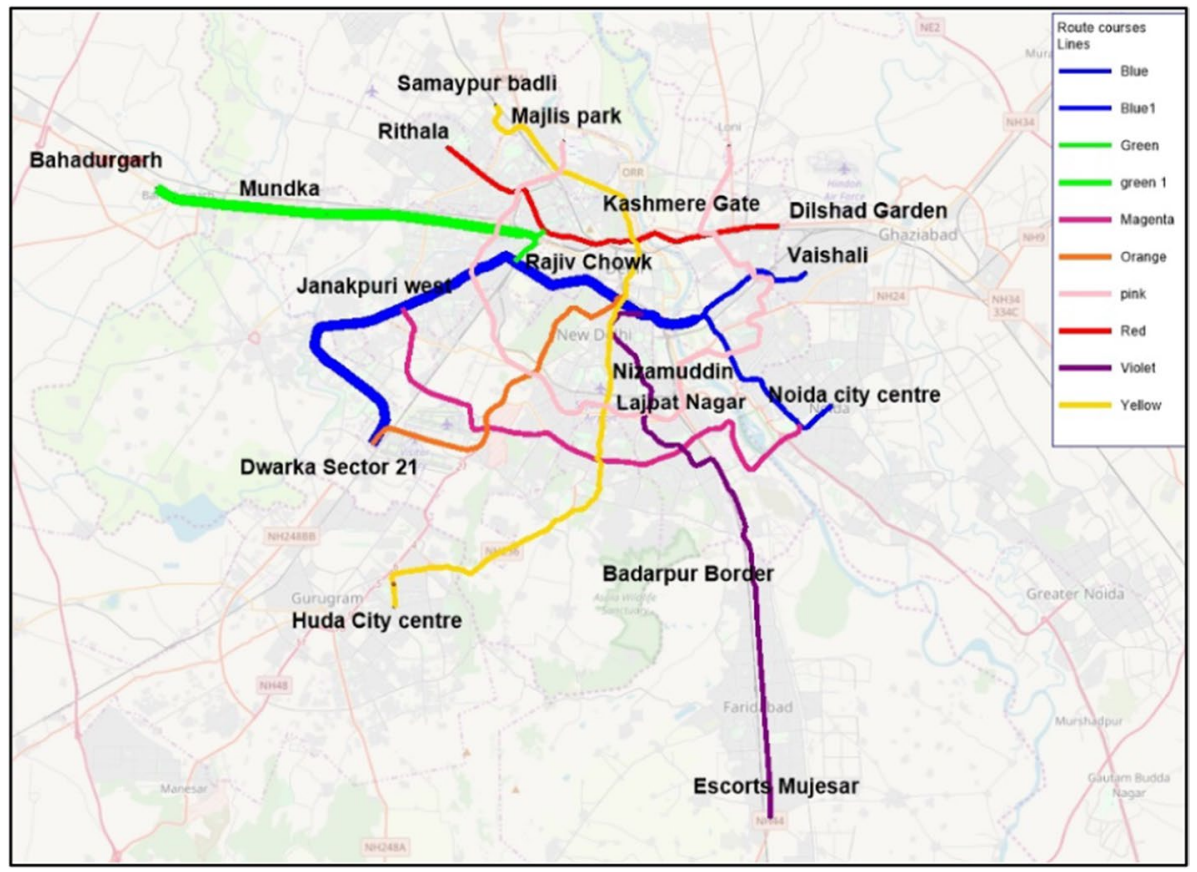




\section{Methodology}
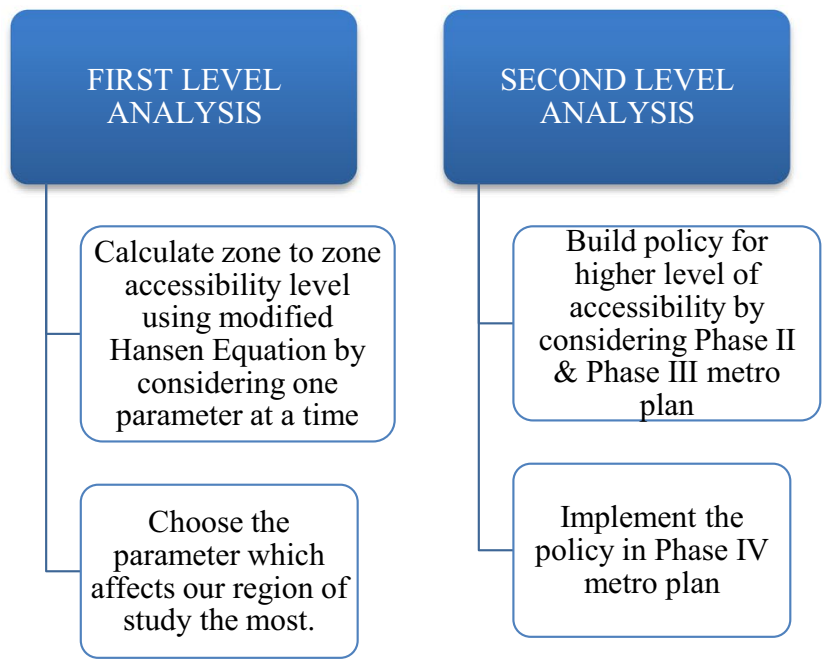

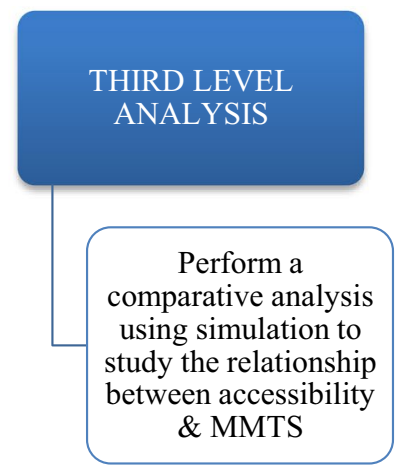

In this study, we have analysed the accessibility at three levels. Firstly, the zone to zone accessibility of Delhi metro for work trip by considering five different parameters is compared. The analysis is carried out by considering one parameter at a time to find the most influential parameter. Accessibility is analysed on the basis of JRT, JRD, DID, OVTT and Impedance with the help of ArcGIS and through macrosimulation in VISUM software. The Metro network of phase II and phase III (Figs. 1, 2) form the basis of further analysis of extracting the study parameters. With the help of primary data and secondary data, four stage modelling is performed in macrosimulation software and the metro skim matrix of JRT, JRD, DID, ACT (Access time), EGT (Egress time), TWT (Transfer waiting time) and Impedance were extracted. Since ACT, EGT and TWT are the out vehicle time, thus they are considered together as OVTT parameter for the study. In the accessibility analysis, we have considered distance and time spent by the public inside the metro and outside the metro. For the accessibility measure, we have used Hansen formula (Eq. 1) which is based on the gravity model, to measure the opportunity which is available in each zone to travel to other zone using the metro as the main mode to derive zone to zone accessibility presented in Eq. (2).

$A_{i j m}=\sum_{j} B_{j} f\left(C_{i j}\right)$

where $A_{i j m}$ is the accessibility of zone $i$ to zone $j$ for the work using metro. $B_{j}$ is the attractiveness of zone $\mathrm{j}$ for a work purpose. $f\left(C_{i j}\right)$ is the function to represent the travel cost from zone $i$ to $j . f\left(C_{i j}\right)=1 / C$, where $C$ is the value of OD metro skim matrices for JRT, JRD, DID, OVTT and Impedance.

In this study, we have considered $\mathrm{Bj}$ as the attractiveness of zone $\mathrm{j}$ for work that is the employment in the zone $j$. Skim matrix of various parameters for metro is used as travel cost function. Further, the results of accessibility level are analysed using ArcGIS and comparison is done between the different parameters that affect the zone to zone accessibility by using metro as the main mode.

In the second level of study, policy for a higher level of accessibility is discussed. For the study, isochrones time for PuT was drawn for the Delhi metro using VISUM software. Isochrones time for zone to stop and metro stop to stop were drawn. The analysis was carried out for phase II and Phase III. The further policy is implemented in the form of Phase IV Delhi metro plan, by considering the horizontal year 2021 study. And again accessibility level is measured with the help of Hansen equation and GIS software after implementing Phase IV.

At last, to analyse the importance of accessibility and to explore the relationship between accessibility and MMTS, the third stage of analysis is carried out. For this study, south Delhi region is considered as study area which is divided into 55 zones, 51 internal zones and 4 external zones. Traditional four stage traffic assignment and multimodal traffic assignment (MMTA) was carried out in macrosimulation software VISUM for the base year 2018. MMTA is done with metro as the main mode (obligatory) and rest modes as the feeder for the metro service. Further isochrones time for private (PrT) for the four stage traffic assignment and MMTA were drawn. 
Table 1 Number of zones in different accessibility level for parameters for current scenario (2018)

\begin{tabular}{lrrrrr}
\hline $\begin{array}{l}A_{i} \text { (accessibil- } \\
\text { ity-levels) }\end{array}$ & JRT & JRD & DID & OVTT & Impedence \\
\hline 1 & 0 & 0 & 0 & 18 & 1 \\
2 & 12 & 0 & 0 & 32 & 15 \\
3 & 15 & 12 & 3 & 53 & 16 \\
4 & 27 & 31 & 19 & 76 & 39 \\
5 & 48 & 78 & 57 & 62 & 56 \\
6 & 66 & 74 & 82 & 63 & 73 \\
7 & 89 & 92 & 96 & 38 & 92 \\
8 & 67 & 40 & 76 & 13 & 46 \\
9 & 33 & 25 & 22 & 3 & 21 \\
10 & 3 & 8 & 5 & 2 & 1 \\
\hline
\end{tabular}

\section{Results and Discussions}

\subsection{Accessibility Measure}

Analysis for zone to zone accessibility for work purpose through metro was done with the help of modifying Hansen equation. The gravity-based model has been developed using derived travel demand parameters JRD, JRT, DID, OVTT and Impedance, and results were analysed by using GIS. Table 1 depicts the number of zones that are lying within a particular accessibility level for the different parameters using Hansen equation. Accessibility level is defined from 1 to 10 , with 1 as the lowest accessible, 5 as average and 10 as highest accessible level. Figure 3 depicts the pictorial view to show the difference between various parameters for accessibility measure.

It can be seen from Table 1 and Fig. 3 that accessibility, according to JRT, JRD, DID and Impedance, is equal and above than average, i.e. equal to level of accessibility 5 and above for most of the zones, whereas, according to OVTT, accessibility is less than average for most of the zones. Based on distance, zone to zone accessibility is above average but when accessibility is measured on the basis of access time, egress time and transfer waiting time then accessibility is poor for most of the zones. For a city like Delhi, accessibility is much more dependent upon time than the distance. Since Delhi has $1749 \mathrm{~km}$ of road length per $100 \mathrm{~km}^{2}$, has one of the highest road densities in India, still facing the congestion on roads (Centre of Science and Environment 2017). Accessibility not only depends upon 'In vehicle travel time' by metro but also depends upon other three parameters of time. First, the time taken to reach the metro station from origin, i.e. access time. Second, the time spent to transfer from one mode to other mode, i.e. transfer waiting time. Third, the time taken to reach the destination after completing the journey from metro, i.e. egress time (Moyano et al. 2018; Kujala et al. 2018).

Figure $4 \mathrm{a}-\mathrm{e}$ are the extracted results from GIS, showing accessibility heat map for different zones with a different shade. With the help of GIS output heat map, it was observed that accessibility in the inner zones is higher as compared to the outer zones in North Delhi, West Delhi, East Delhi, and South Delhi region. This result can be explained with the help of Delhi metro routes. In Fig. 2, we can see that in the central part of the Delhi, connectivity of the metro lines with the central area is better than the outer region. Due to the higher level of connectivity in the central part, zones in central Delhi have lesser OVTT for metro, i.e. less access, egress and transfer waiting time as compared to outer zones in North, West, East and South Delhi.

To understand how accessibility is varying across different zones, we have carried out a detailed exploration by listing out the zones on the basis of the highest score on the accessibility scale. Table 2 consists of 5 most accessible zones (in descending order) according to different parameters in the accessibility analysis. In Table 2, we can see that
Fig. 3 Graph between accessibility level and number of zones for current scenario (2018)

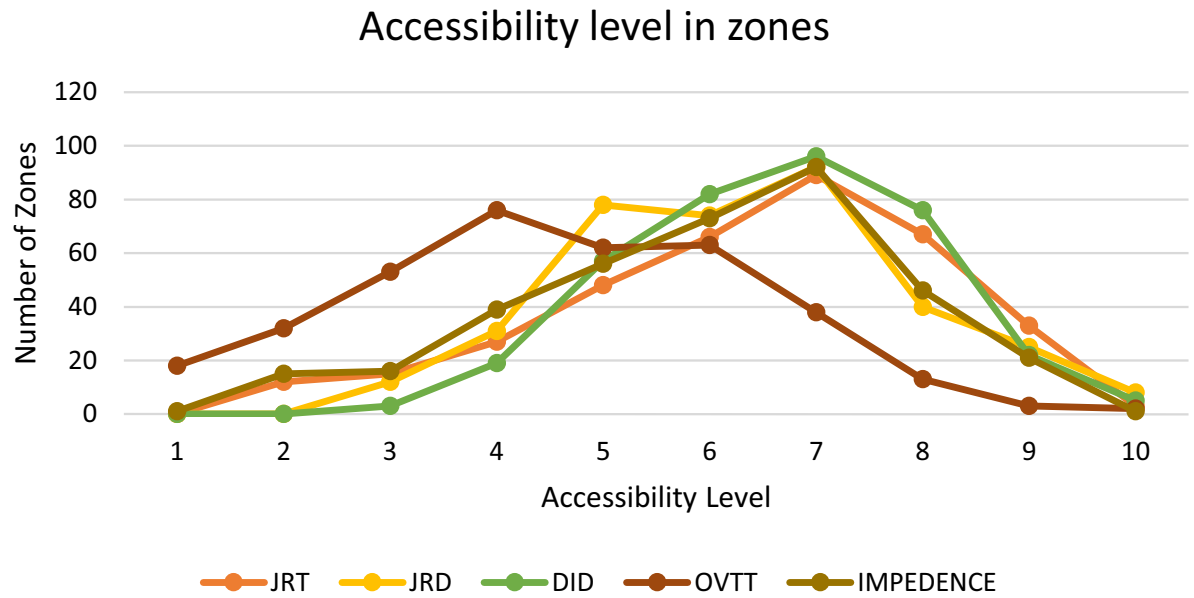




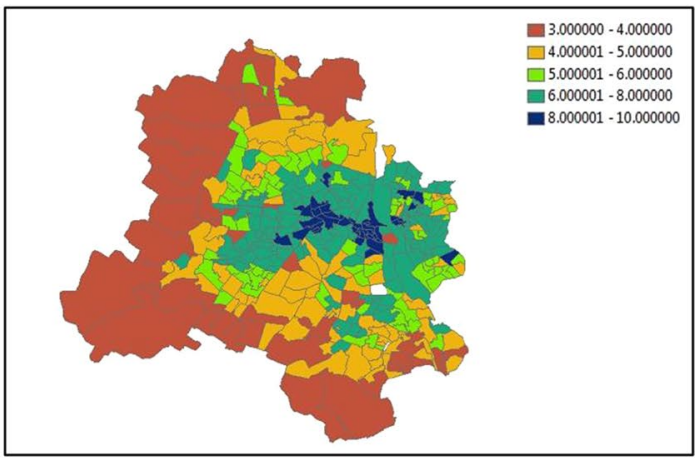

a Heat map of zonal accessibility based on journey distance for current scenario (2018)

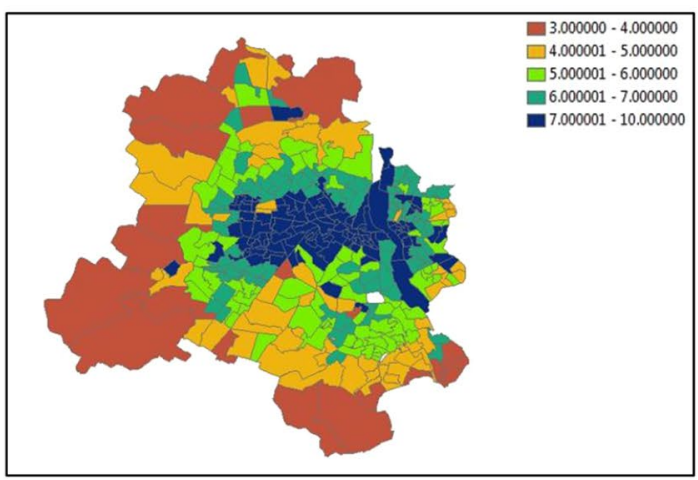

c Heat map of zonal accessibility based on direct distance for current scenario (2018)

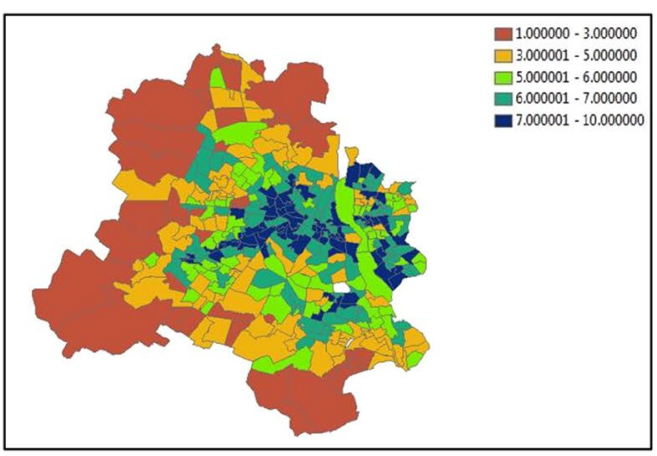

e Heat map of zonal accessibility based on Impedance for current scenario (2018)

Fig. 4 a Heat map of zonal accessibility based on journey distance for current scenario (2018), b Heat map of zonal accessibility based on journey time for current scenario (2018), c Heat map of zonal accessibility based on direct distance for current scenario (2018), d

most of the zones are different for the different parameter. For JRT and Impedance parameter, 3 of the zones out of 5 are same, it is because impedance is combined parameter in which JRT is one of the parameter and according to other parameters zones are almost different.

These zones are listed as the most accessible zones due to the balance in opportunity and connectivity. Sufficient

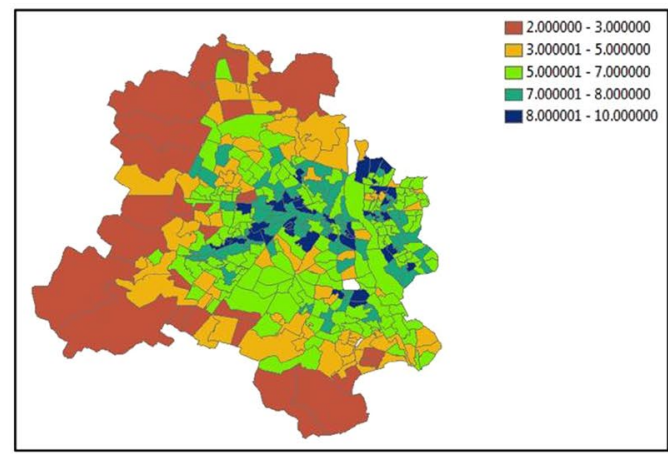

b Heat map of zonal accessibility based on journey time for current scenario (2018)

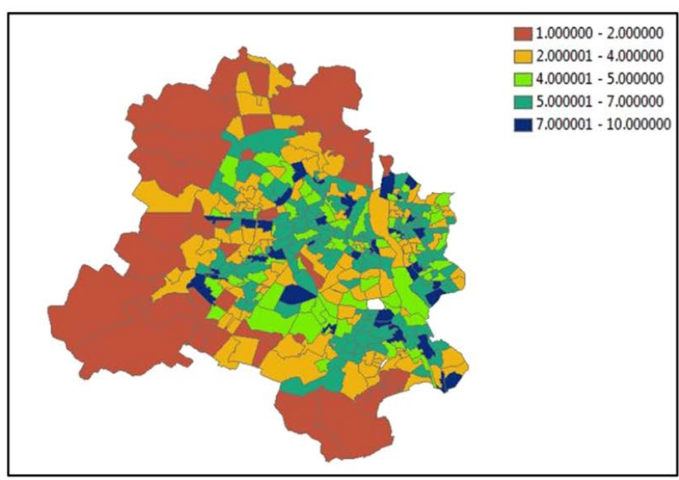

d Heat map of zonal accessibility based on out vehicle travel time for current scenario (2018)
Heat map of zonal accessibility based on out vehicle travel time for current scenario (2018), e Heat map of zonal accessibility based on Impedance for current scenario (2018)

connectivity is present in these regions to fullfill the public needs of travel for the purpose of work through metro service.

From the above result, it can be concluded that by considering different parameters in accessibility measure, different results are obtained. From these parameters, we need to choose the parameter which affects our region of study 
Table 2 List of most accessible zones for different parameters for current scenario

\begin{tabular}{llllll}
\hline Rank & Parameter & & & & Impedance \\
\cline { 2 - 5 } & JRT & JRD & DID & OVTT & Janta Colony \\
1 & Janta Colony & Bazar Sita Ram & Idgah Road & Samaypur Badli & Rajouri Garden \\
2 & Dharam Pura & Jama Massjid & Model Basti & Baird Place, Khyber Lines & New Ranjit Nagar \\
3 & Rajouri Garden & Shastri Nagar & Ram Nagar & Shiv Vihar & Baljit Nagar \\
4 & New Ranjit Nagar & Qasabpura & Kuncha Pandit & East Of Kailash & Wazirpur \\
5 & Baljit Nagar & Janta Colony & Nimri Colony & Shakarpur & \\
\hline
\end{tabular}

Table 3 Isochrones time PuT(metro) from zone Nizamuddin

\begin{tabular}{lll}
\hline Station & Phase II & Phase III \\
\hline Mundka & $1 \mathrm{~h} 32 \min 17 \mathrm{~s}$ & $1 \mathrm{~h} 16 \min 41 \mathrm{~s}$ \\
Huda City & $1 \mathrm{~h} 33 \min 47 \mathrm{~s}$ & $1 \mathrm{~h} 14 \min 54 \mathrm{~s}$ \\
Rithala & $1 \mathrm{~h} 38 \min 17 \mathrm{~s}$ & $1 \mathrm{~h} 17 \min 54 \mathrm{~s}$ \\
Azadpur & $1 \mathrm{~h} 10 \min 47 \mathrm{~s}$ & $58 \min 54 \mathrm{~s}$ \\
Hauz khas & $52 \min 47 \mathrm{~s}$ & $33 \min 54 \mathrm{~s}$ \\
INA & $42 \min 17 \mathrm{~s}$ & $23 \min 54 \mathrm{~s}$ \\
ISBT & $47 \min 17 \mathrm{~s}$ & $30 \min 24 \mathrm{~s}$ \\
Botanical Garden & $53 \min 17 \mathrm{~s}$ & $30 \min 41 \mathrm{~s}$ \\
Welcome & $1 \mathrm{~h} 1 \min 17 \mathrm{~s}$ & $40 \min 24 \mathrm{~s}$ \\
Noida Sector 15 & $47 \min 17 \mathrm{~s}$ & $24 \min 41 \mathrm{~s}$ \\
\hline
\end{tabular}

the most. In a developing city like Delhi with good transport infrastructure and large road network, the only reason left for not using MMTS is accessibility for public transport in terms of time. Therefore, it can be concluded from the measure of accessibility result that OVTT is the most affecting parameter. Thus to help the planner to escape from the complexity of study for the large network, it is required to find the parameter which is more important and which affects the region of study the most for accessibility.

\subsection{Policy for Higher Accessibility}

As discussed earlier, that accessibility is much more dependent upon the OVTT that is the access time, egress time and transfer waiting time; a reduction in this component should lead to increase in the zone to zone accessibility. With this intention, analysis and comparison of change in accessibility due to the expansion of metro from Phase II to Phase IV are done.

In phase III as shown in Fig. 2, two new metro lines were introduced: Magenta line (from Botanical Garden to Janakpuri West) and Pink line (from Majlis park to Shiv vihar) along with the extension of Red, Yellow, Green, Violet lines. Table 3 shows the difference in travel time due to the introduction of phase III metro plan from Nizamuddin zone to other important metro stations, situated in different regions of Delhi. Nizamuddin is located in south Delhi, having denser population, surrounded by Nizamuddin Dargha and railway station which is one of the 5 main railway stations in Delhi, connecting all the major cities. Figure 5a, b show the isochrones time for PuT from Nizamuddin zone to all the metro station with the column over various metro stations, showing the travel time for phase II and phase III, respectively. From this result, we observed that travel time from Nizamuddin zone to other metro stations was reduced after the implementation of phase III plan. Similarly, for other zones, the same results were observed. We have observed this from Figs. 1 and 2 that in phase III, connectivity between various stations with Nizamuddin zone is improved due to the introduction of a pink line from Nizamuddin zone with the addition of Nizamuddin metro station in phase III. Due to this, travel time between stations were reduced.

Similarly, in Table 4, isochrones time PuT from Lajpat nagar metro station to other important metro stations were shown for phase II and phase III. Lajpat nagar is a major commercial and residential area. Figure $6 \mathrm{a}, \mathrm{b}$ show the isochrones time PuT from Lajpat nagar metro station to other metro stations with a column over metro stops showing travel time to various metro stations from Lajpat nagar metro station. It was observed that 'In vehicle travel time' is reduced from Lajpat nagar metro stops to other stops after the implementation of phase III metro. From Figs. 1 and 2, we can observe that in addition of a violet line, the pink line is also introduced, passing through Lajpat nagar metro station and nearby magenta line is also introduced. Due to this, travel time is reduced from the Lajpat nagar metro station to the other stops. Similarly, for other zones and stops, travel time is reduced.

From the above results, it can be concluded that due to the extension and introduction of the new metro line, travel time is reduced between zones and metro stops to other metro stops. Further, new metro stations were introduced in phase III; this improves the accessibility of zones as less access and egress distances need to travel for metro. In current scenario, service frequency of metro is increased which helps in reducing transfer wait time as in peak hour frequency is $2 \mathrm{~min}$ to $3 \mathrm{~min}$ and in off-peak hour it is $4 \mathrm{~min}$ to $6 \mathrm{~min}$. 


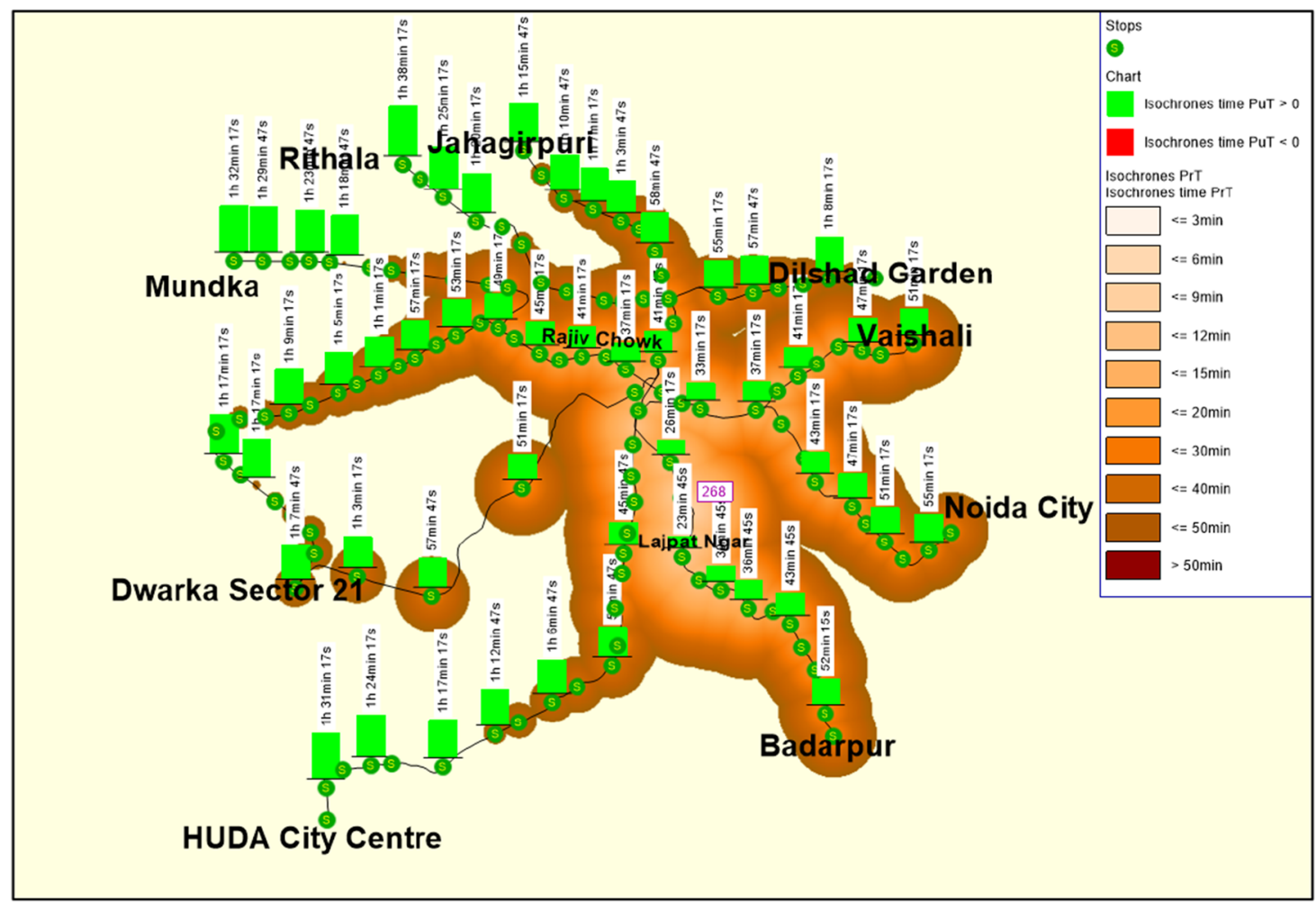

a Isochrones of travel time from Nizamuddin zone (phase II)

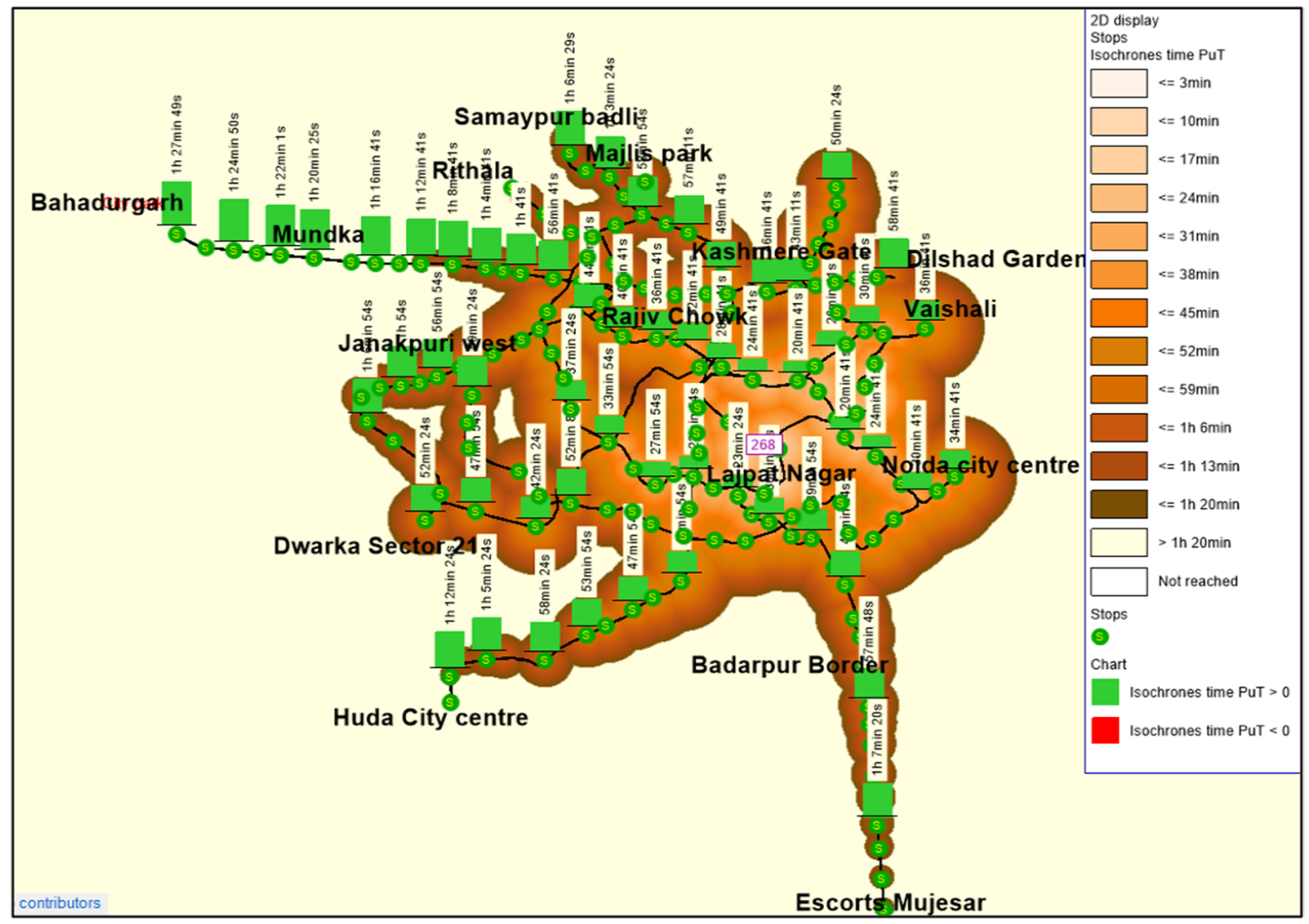

b Isochrones of travel time from Nizamuddin zone (phase III)

Fig. 5 a Isochrones of travel time from Nizamuddin zone (phase II), b Isochrones of travel time from Nizamuddin zone (phase III) 
Table 4 Isochrones time PuT(metro) from Lajpat Nagar metro stop point

\begin{tabular}{lll}
\hline Metro stops & Phase II & Phase III \\
\hline Mundaka & $1 \mathrm{~h} 18 \mathrm{~min}$ & $1 \mathrm{~h} 6 \mathrm{~min} 30 \mathrm{~s}$ \\
Huda City Centre & $1 \mathrm{~h} 19 \mathrm{~min} 30 \mathrm{~s}$ & $54 \mathrm{~min} 30 \mathrm{~s}$ \\
Rithala & $1 \mathrm{~h} 24 \mathrm{~min}$ & $57 \mathrm{~min} 30 \mathrm{~s}$ \\
Azadpur & $56 \mathrm{~min} 30 \mathrm{~s}$ & $38 \mathrm{~min} 30 \mathrm{~s}$ \\
Hauz Khas & $38 \mathrm{~min} 30 \mathrm{~s}$ & $13 \mathrm{~min} 30 \mathrm{~s}$ \\
INA & $28 \mathrm{~min}$ & $3 \mathrm{~min} 30 \mathrm{~s}$ \\
ISBT & $33 \mathrm{~min}$ & $24 \mathrm{~min}$ \\
Botanical Garden & $39 \mathrm{~min}$ & $24 \mathrm{~min} 17 \mathrm{~s}$ \\
Welcome & $47 \mathrm{~min}$ & $34 \mathrm{~min}$ \\
Noida Sector 15 & $33 \mathrm{~min}$ & $18 \mathrm{~min} 17 \mathrm{~s}$ \\
\hline
\end{tabular}

Figure 7 shows the metro phase IV which is going to be completed in 2025. In Phase IV, two new metro lines are going to be constructed. First, moss green line from Tughlakabad to T1 IGIA and Lajpat nagar to Saket G block and second aqua line from Inderlok to Indraprastha. Further extension of red, pink and magenta line is going to take place.

Accessibility analysis was carried out after taking phase IV metro construction in consideration, and results were extracted for the same parameters as shown in Table 5 and Fig. 8

Figure 9a-e show GIS result for different parameters after considering phase IV metro plan. From the comparison between accessibility analysis for the current scenario and accessibility after implementation of phase IV metro, it was observed that according to JRT parameter, zones having lower accessibility shift towards average accessibility level. For JRD parameter, not much difference was observed and for DID parameter no change was observed. The great effect is observed in accessibility for OVTT parameter. Earlier, around 179 zones out of 360 were in lower accessibility category but after implementation of phase IV, number of zones in the lower accessibility category reduced to 112 zones. Similarly according to impedance factor around 20 zones shift towards average accessibility level and approx. 15 zones shift to an above average level.

The above results show that to make metro accessible from all the zones, it is needed to consider OVTT and impedance as major parameters in policy making based on the accessibility. But as we know that impedance is the combination of different parameters such as travel distance, travel time, and travel cost and for this study, we are finding a way to measure accessibility with lesser data. Thus, considering OVTT is the better way in policy making based on the accessibility. A similar study by Kumar et al. (2013) concluded that for making multimodal transport system attractive, accessibility for the main mode should be high with less access and egress time. From this, we can say that OVTT is the major parameter in the accessibility analysis.

Tables 6 and 7 show the result of Isochrones time PuT for current scenario, and after implementation of phase IV, we can observe from above Tables 6 and 7 that zone to stop and stop to stop time is reduced after the construction of Phase IV metro plan.

It can be observed from the above results that as the Delhi metro lines are expanding, accessibility is improving. When phase III was constructed, accessibility increased as compared to earlier. When the phase IV plan was included, then accessibility was further improved as compared to the current scenario. Hence, one of the ways to improve accessibility is by making metro available (Bocarejo and Oviedo 2012). This can be achieved by making policy for transport planning on the basis of accessibility and not on future forecasting.

\subsection{Policy Simulation-Accessibility and MMTS}

The study is carried out to relate the accessibility of private transport with the MMTS which is further related to the accessibility of PuT. For this isochrones time for private (PrT) for the four stage traffic assignment and MMTA were compared. Accessibility is analysed by observing the shift of private transport user to public transport. Figure 10a shows the isochrones time PrT from the Sukhdev Vihar zone 206 for four stage traffic assignment. If we compare this isochrones time PrT with Fig. 10b showing the isochrones time PrT from the same zone for multimodal traffic assignment, we can see that in the multimodal scenario, time of travel is reduced, i.e. accessibility is increased. This is due to the shift from private transport to public transport in MMTS scenario. Here, we can conclude that if people prefer metro as the main mode and rest the modes as a feeder for the metro service then accessibility will improve and if accessibility for metro is high then people will prefer metro as the main mode for their journey.

People prefer to move with the mode of transport which is more convenient, safe, takes less travel time, and is economic. If a planner wants to shift the people to use public transport system instead of using private than facilities for MMTS should be provided. For that, accessibility to public transport and accessibility by the public transport should be high.

Further, if people use MMTS, then private traffic on roads will reduce which further helps in reducing environmental pollution (both noise as well as air pollution). We can say that planning towards MMTS and making policy based on accessibility will help in the sustainable development of the transport system. 


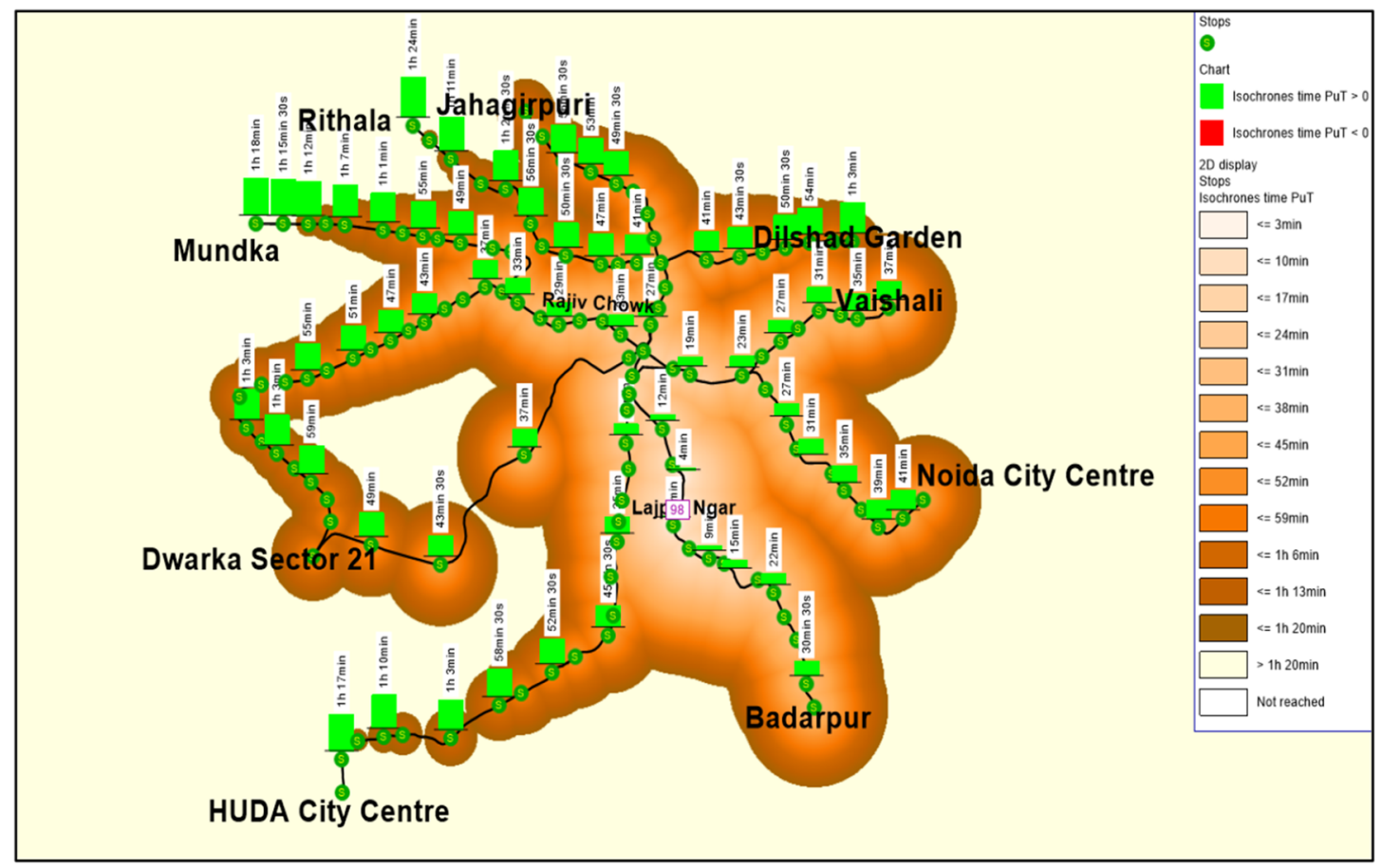

a Isochrones time from Lajpat nagar metro stop point (phase II)

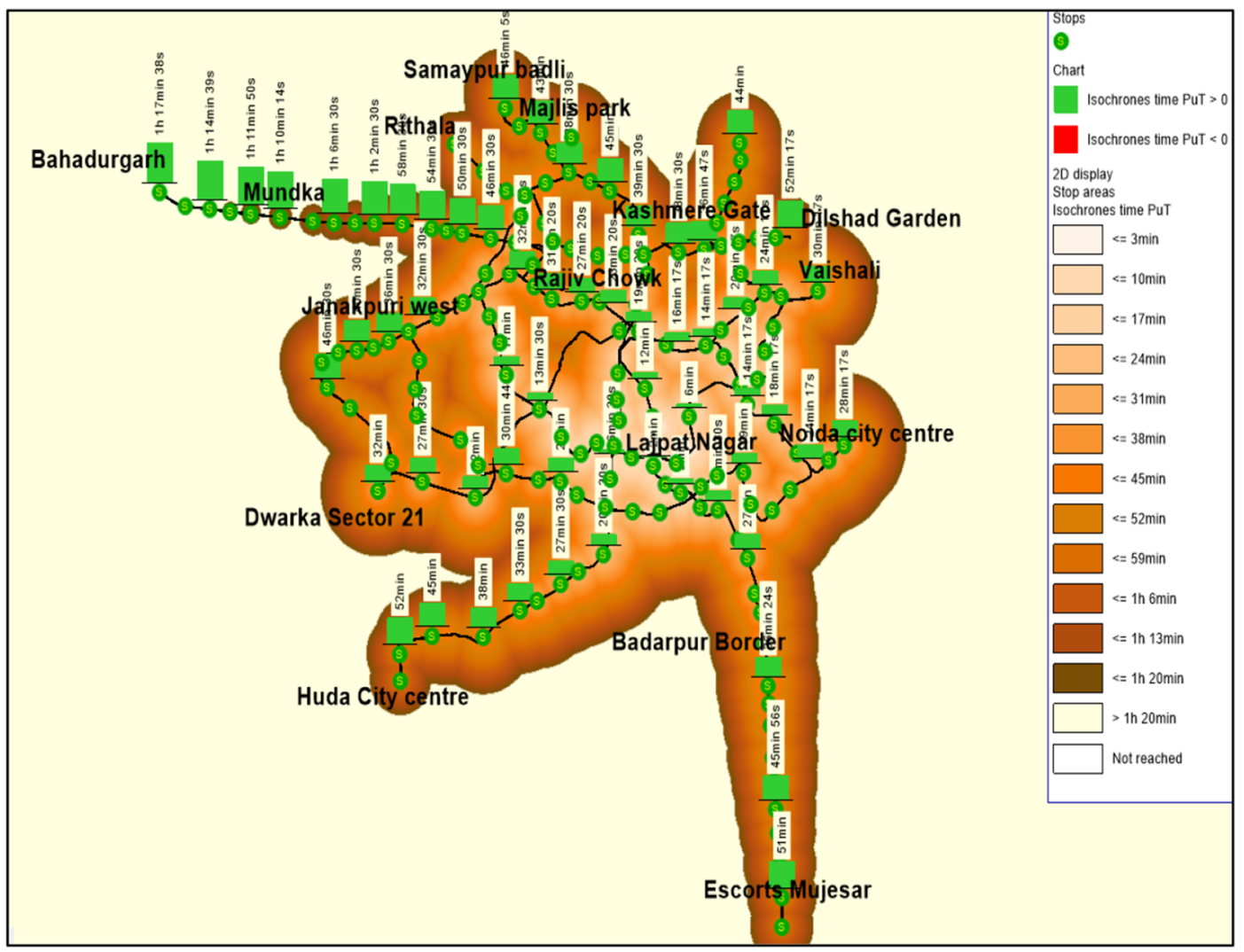

b Isochrones time from Lajpat nagar metro stop point (phase III)

Fig. 6 a Isochrones time from Lajpat nagar metro stop point (phase II), b Isochrones time from Lajpat nagar metro stop point (phase III) se? 
Fig. 7 Delhi metro Phase IV

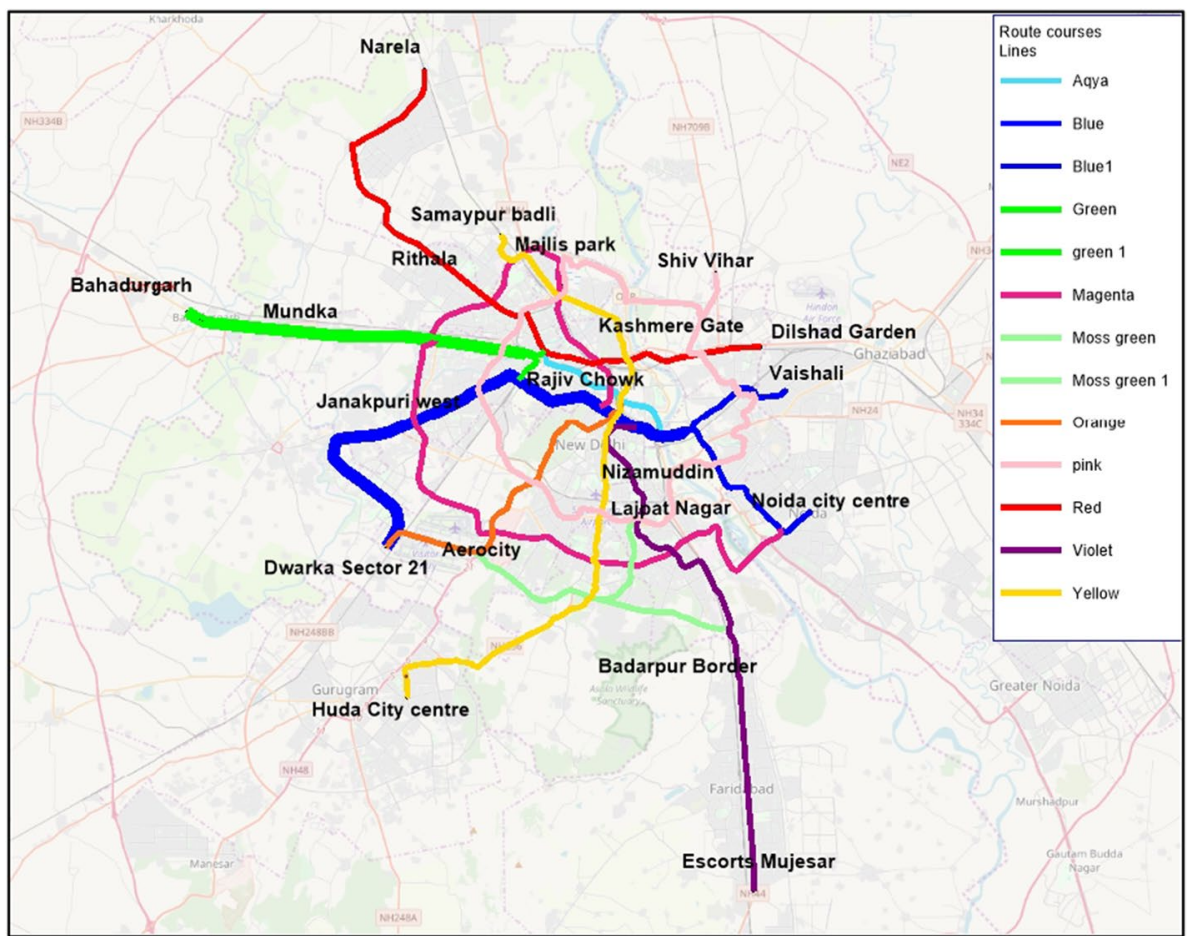

\section{Conclusion and Recommendations}

This paper discussed the policy that can be effectively used in Delhi to increase the zone to zone accessibility through metro for work purpose. Using macrosimulation software VISUM, skim matrices of different parameter JRD, JRT, DID, OVTT and Impedance were extracted for metro. These parameters were used in the gravity-based model, Hansen equation to measure zone to zone metro accessibility for work purpose. Finally, this accessibility result was given as input in GIS to get heat maps for a pictorial view of zonewise accessibility level for different parameters. Further, isochrones time of PuT for Nizamuddin zone and Lajpat

Table 5 Number of zones in different accessibility level for parameters after Phase IV metro implementation

\begin{tabular}{lcrrcc}
\hline$A_{i}$ & JRT & JRD & DID & OVTT & Impedence \\
\hline 1 & 0 & 0 & 0 & 7 & 0 \\
2 & 7 & 0 & 0 & 11 & 0 \\
3 & 11 & 6 & 3 & 35 & 6 \\
4 & 31 & 34 & 19 & 59 & 30 \\
5 & 60 & 76 & 57 & 62 & 75 \\
6 & 92 & 83 & 82 & 75 & 82 \\
7 & 85 & 92 & 96 & 61 & 92 \\
8 & 47 & 41 & 76 & 41 & 41 \\
9 & 25 & 23 & 22 & 7 & 23 \\
10 & 2 & 5 & 5 & 2 & 5 \\
\hline
\end{tabular}

nagar metro station to other important metro stops for Phase II, Phase III and Phase IV were observed. At last, policy for accessibility is compared with the MMTS in VISUM by taking South Delhi as the study area.

From the accessibility level results for different parameters for the current scenario (2018), it was observed that the zones in the central part of Delhi region are having higher accessibility level as compared to other zones. However, after considering phase IV, accessibility level is improved up to a certain level. Further, for the current scenario (2018), it was observed that the accessibility level for OVTT parameter is below the average level for most of the zones whereas for other parameters it is equal to or above average. However, after considering phase IV, accessibility level for OVTT parameter is improved and for other parameters, not much difference was observed. From the isochrones results, it was observed that as the metro line in expanding from Phase II to phase III, travel time is reduced from zone to metro stops and metro station to station, further time is reduced when phase IV is also implemented. Thus, accessibility level results help in finding the accessibility measure and with isochrones result, policy for accessibility was found for the developing a city like Delhi.

At last relation between MMTS and accessibility is explored with South Delhi as the study area. With the isochrones of PrT time results, it was clear that by using MMTS, congestion on road is reduced. That means accessibility for PrT is improved. Most of the private vehicle users shift towards public transport with metro as the main mode and 
Fig. 8 Graph between accessibility level and number of zones after Phase IV metro implementation

\section{Accessibility level in zones}

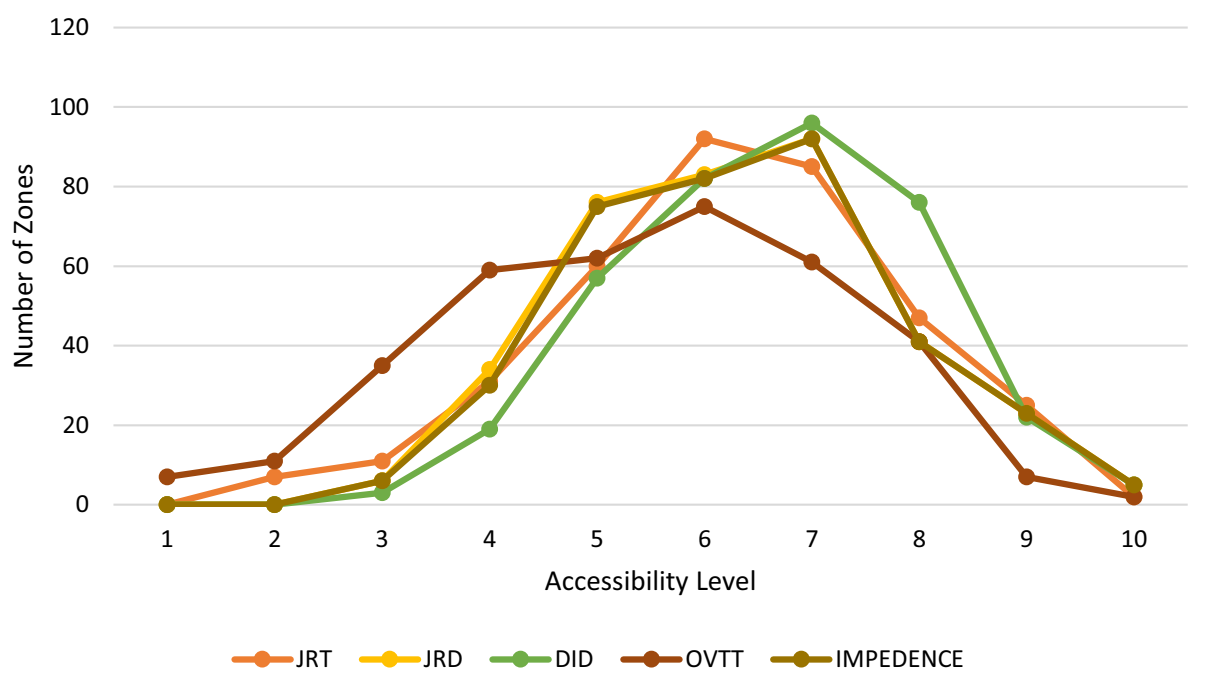

using private vehicle for a short path in their journey. It can be concluded from this study that by measuring accessibility using a major parameter and applying the policy for that, will help in improving the accessibility of a city like Delhi. Further, this improvement in accessibility will help in shifting of people towards public transport which will reduce the load on the roads and further, help in developing the city in a sustainable manner.

From this study of Delhi region, it can be concluded that OVTT is an important parameter in accessibility analysis as compared to other parameters, and to improve the metro accessibility OVTT should be reduced. For that, facilities like Park and Ride, Bike and Ride, sufficient space for parking, feeder services, and integration of feeder services with metro are a pre-requirement. Also, the availability of metro in walkable distance and safe environment for the pedestrian are also needed to improve metro accessibility.

The study is carried out at three different levels: the measure of accessibility, policy for accessibility and at last the relation of accessibility with MMTS. From these results of the study, we can conclude that the use of policy for accessibility for planning a city like Delhi will help in the development of the city in a sustainable manner. Due to increase in population and migration of people from nearby places to Delhi for work, education and business, Delhi roads and environmental condition are becoming worse. To improve accessibility, it is required to make policy revolving around accessibility. This paper discussed the policy that the accessibility will be improved by expanding the metro network and by making metro available in walkable distance. With the improvement in accessibility through metro, air and noise pollution will reduce due to reduced congestion on roads as commuters will prefer MMTS.
Table 6 Isochrones PuT from Nizamuddin to major metro stops for phase III and phase IV

\begin{tabular}{lll}
\hline Metro stops & Phase III & Phase IV \\
\hline Mundaka & $1 \mathrm{~h} 16 \min 41 \mathrm{~s}$ & $1 \mathrm{~h} 6 \min 30 \mathrm{~s}$ \\
Huda City Centre & $1 \mathrm{~h} 14 \min 54 \mathrm{~s}$ & $54 \min 30 \mathrm{~s}$ \\
Rithala & $1 \mathrm{~h} 17 \min 54 \mathrm{~s}$ & $57 \min 30 \mathrm{~s}$ \\
Azadpur & $58 \min 54 \mathrm{~s}$ & $38 \min 30 \mathrm{~s}$ \\
IIT & $44 \min 24 \mathrm{~s}$ & $32 \min 54 \mathrm{~s}$ \\
New Delhi & $34 \min 41 \mathrm{~s}$ & $32 \min 16 \mathrm{~s}$ \\
Tughlaqabad & $51 \min 54 \mathrm{~s}$ & $41 \min 49 \mathrm{~s}$ \\
Chirag Delhi & $38 \min 24 \mathrm{~s}$ & $24 \min 24 \mathrm{~s}$ \\
T1 IGIA & $53 \min 53 \mathrm{~s}$ & $42 \min 54 \mathrm{~s}$ \\
\hline
\end{tabular}

Apart from this, study fares of the metro can also be considered as one of the reasons for not opting metro. This study can be extended by using fares of the metro as a parameter. Delhi metro fare is high and it will be higher after the execution of phase IV metro plan. This might restrict the lower income group and students to prefer metro.

Table 7 Isochrones PuT from Lajpat nagar metro station to major stops for phase III and phase IV

\begin{tabular}{lll}
\hline Metro stops & Phase III & Phase IV \\
\hline Mundaka & $1 \mathrm{~h} 6 \mathrm{~min} 30 \mathrm{~s}$ & $57 \mathrm{~min}$ \\
Huda City Centre & $54 \mathrm{~min} 30 \mathrm{~s}$ & $45 \mathrm{~min} 30 \mathrm{~s}$ \\
Rithala & $57 \mathrm{~min} 30 \mathrm{~s}$ & $56 \mathrm{~min}$ \\
Azadpur & $38 \mathrm{~min} 30 \mathrm{~s}$ & $36 \mathrm{~min} 43 \mathrm{~s}$ \\
IIT & $23 \mathrm{~min}$ & $13 \mathrm{~min}$ \\
New Delhi & $24 \mathrm{~min}$ & $22 \mathrm{~min} 30 \mathrm{~s}$ \\
Tughlaqabad & $30 \mathrm{~min} 30 \mathrm{~s}$ & $22 \mathrm{~min} 55 \mathrm{~s}$ \\
Chirag Delhi & $17 \mathrm{~min}$ & $5 \mathrm{~min} 30 \mathrm{~s}$ \\
T1 IGIA & $32 \mathrm{~min} 29 \mathrm{~s}$ & $24 \mathrm{~min}$ \\
\hline
\end{tabular}




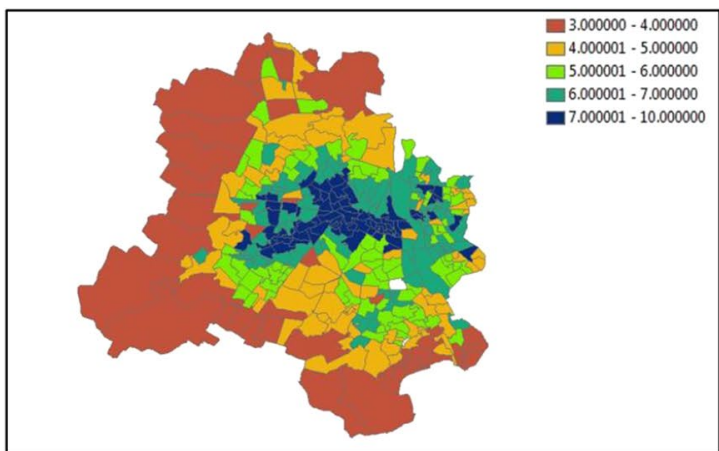

a Heat map of zonal accessibility based on journey distance after phase IV implementation.

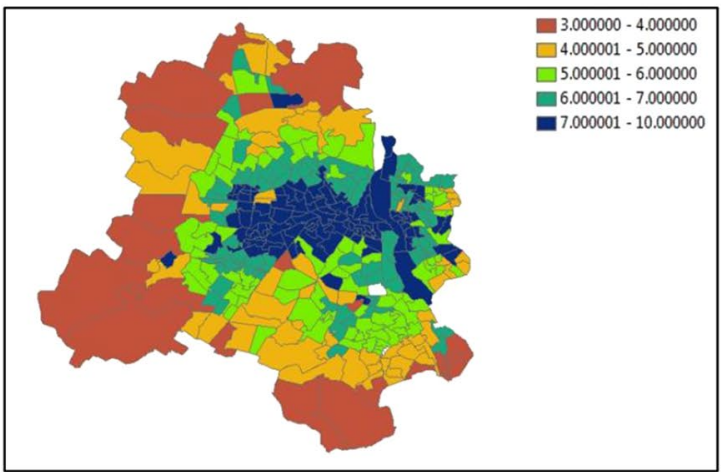

c Heat map of zonal accessibility based on direct distance after phase IV implementation.

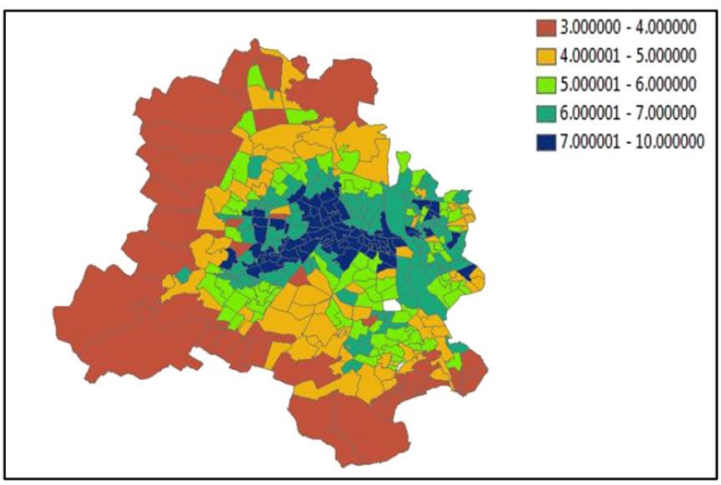

e Heat map of zonal accessibility based on Impedance after phase IV implementation.

Fig. 9 a Heat map of zonal accessibility based on journey distance after phase IV implementation, b heat map of zonal accessibility based on journey time after phase IV implementation, $\mathbf{c}$ heat map of zonal accessibility based on direct distance after phase IV implemen-

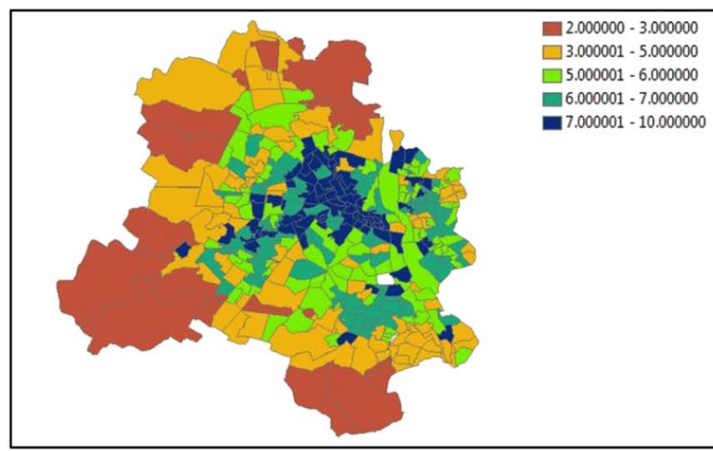

b Heat map of zonal accessibility based on journey time after phase IV implementation

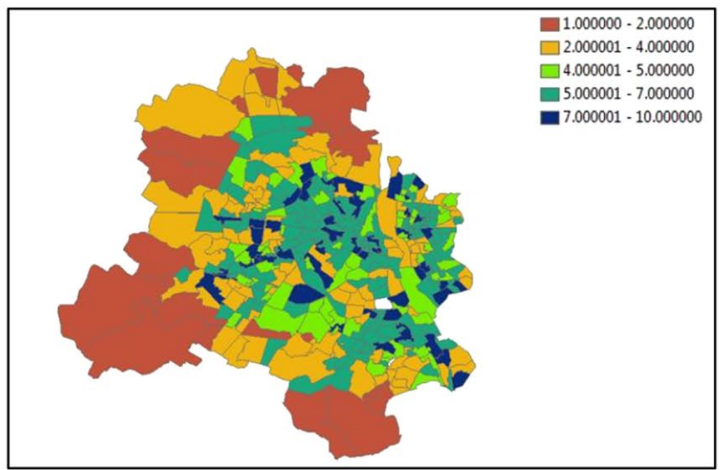

d Heat map of zonal accessibility based on out vehicle travel time after phase IV implementation. tation, $\mathbf{d}$ heat map of zonal accessibility based on out vehicle travel time after phase IV implementation, e heat map of zonal accessibility based on Impedance after phase IV implementation 


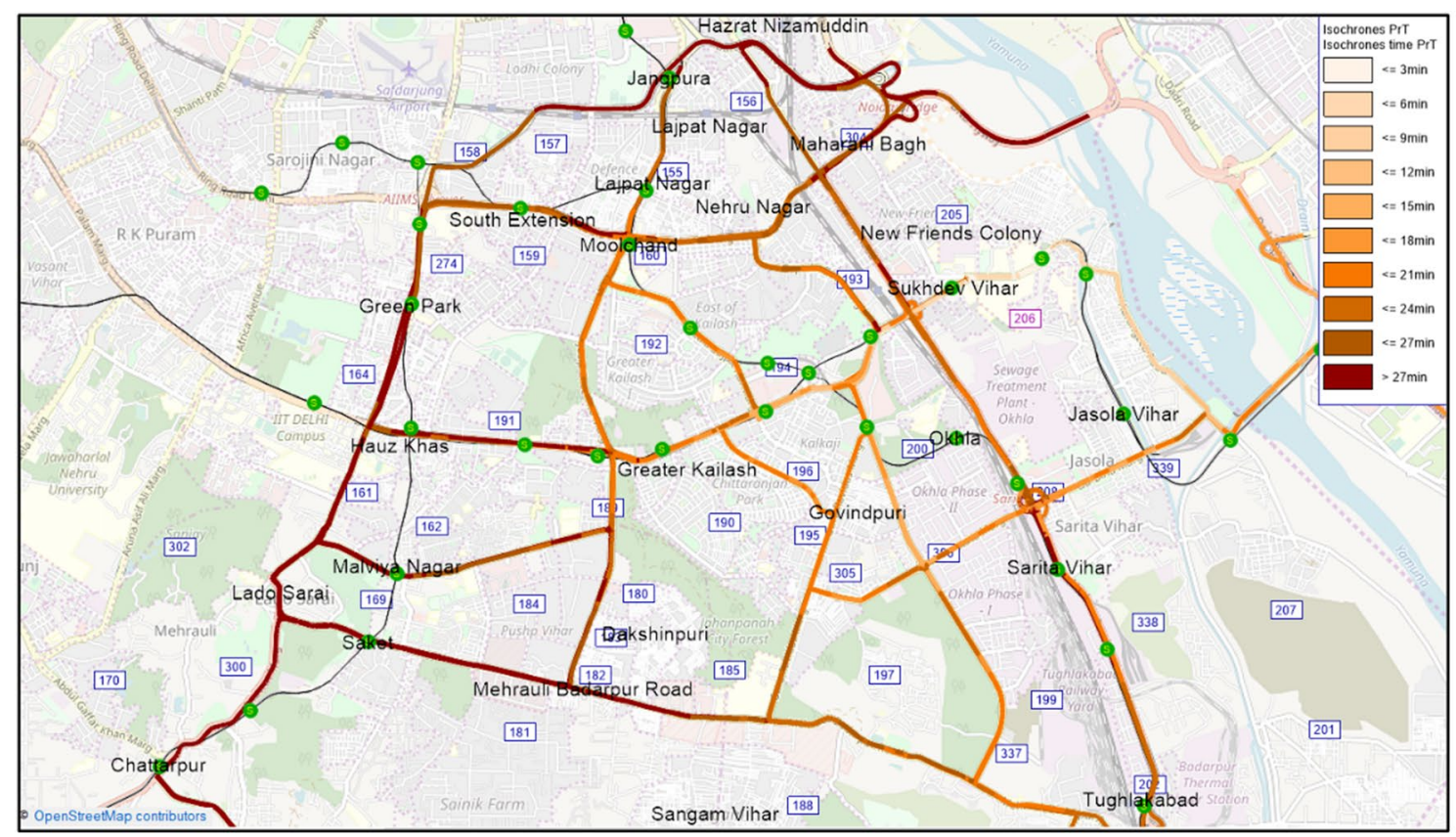

a Isochrones PrT time from Sukhdev vihar zone 206

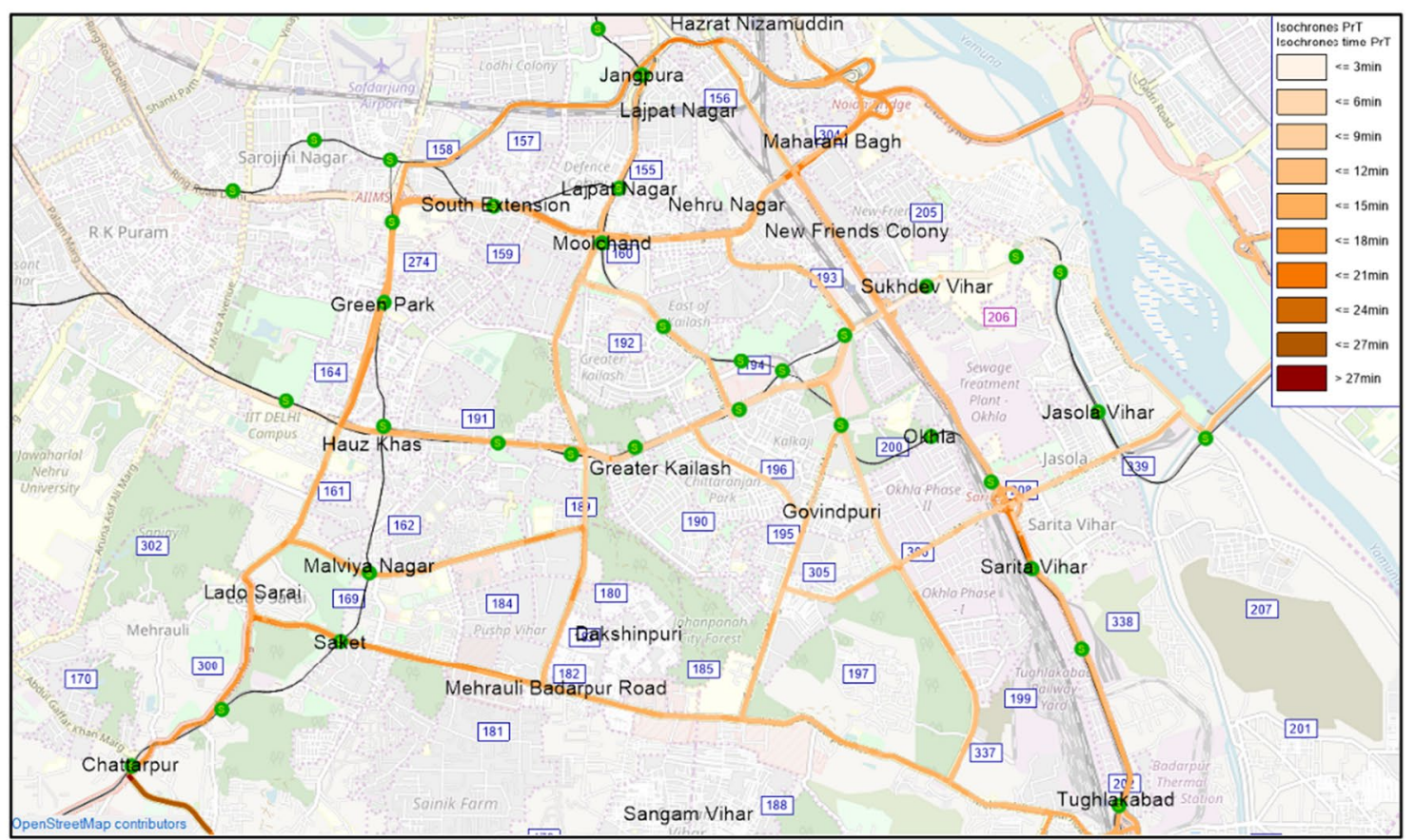

b Isochrones PrT from Sukhdev vihar zone 206 in multimodal transport system

Fig. 10 a Isochrones PrT time from Sukhdev vihar zone 206, b Isochrones PrT from Sukhdev vihar zone 206 in multimodal transport system 
Authors' contribution Author 1: Literature Search and Review, MetaAnalysis, content planning and Manuscript Writing, Author 2: MetaAnalysis, content planning, Manuscript Writing, Editing and proofing.

Funding Funding from Project OLP-0603 sponsored by CSIR-Central Road Research Institute, India, was received to assist with the preparation of this manuscript.

Availability of Data and Materials The data that support the findings of this study are openly available at DDA website.

Code Availability The datasets generated during the current study are available from the corresponding author on reasonable request.

\section{Declarations}

Conflict of interest On behalf of all authors, the corresponding author states that there is no conflict of interest.

\section{References}

Al-Sahili K, Aboul-Ella M (1992) Accessibility of public services in Irbid, Jordan. J Urban Plan Dev 118(1):1-12

Bivina G, Gupta A, Parida M (2019) Influence of microscale environmental factors on perceived walk accessibility to metro stations. Transp Res Part D 67:142-155

Black J, Conroy M (1977) Accessibility measures and the social evaluation of urban structure. Environ Plan A 9(9):1013-1031

Bocarejo SJ, Oviedo HD (2012) Transport accessibility and social inequities: a tool for identification of mobility needs and evaluation of transport investments. J Transp Geogr 24:142-154

Centre of science and environment (2017) Congestion on Delhi roads has worsened - says new analysis by CSE of latest Google map data. Centre of science and environment, Delhi

Chang J, Lee J (2008) Accessibility analysis of Korean high-speed rail: a case study of the Seoul Metropolitan Area. Transp Rev 28(1):87-103

Chen C, Varley D, Chen J (2011) What affects transit ridership? A dynamic analysis involving multiple factors, lags and asymmetric behaviour. Urban Stud 48(9):1893-1908

Curtis C (2008) Planning for sustainable accessibility: the implementation challenge. Transp Policy 15(2):104-112

Dalvin MQ, Martin KM (1976) The measurement of accessibility: some preliminary results. Transportation 5(1):17-42

Department for Transport (2018) The inclusive transport strategy: achieving equal access for disabled people. Department for Transport, London

DMRC (2015) Delhi Metro Rail Corporation, Leaders in green and clean mass rapid transit system in India. INDIA @ COP 21, Paris

DMRC (2016) Delhi Metro Rail Corporation Sustainability Report, 2015-2016. DMRC, Delhi

DMRC (2018) Delhi Metro Rail Corporation Annual report, 20172018. DMRC, Delhi

Düring S, Sluka A, Vesely O, König R (2019) Applied spatial accessibility analysis for urban design an integrated graph-gravity model implemented in grasshopper. In: Sousa JP, Henriques GC, Xavier JP (eds) Proceedings of 37 eCAADe and XXIII SIGraDi joint conference, "Architecture in the Age of the 4th Industrial Revolution”, Porto 2019, Sousa, São Paulo, Blucher. ISSN 2318-6968, pp 333-342. https://doi.org/10.5151/proceedings-ecaadesigradi20 19_475
Farber S, Fu L (2017) Dynamic public transit accessibility using travel time cubes: comparing the effects of infrastructure (dis) investments over time. Comput Environ Urban Syst 62:30-40

Ford A, Barr S, Dawson R, James P (2015) Transport accessibility analysis using GIS: assessing sustainable transport in London. ISPRS Int J Geo Inf 4(1):124-149

Frost M, Spence N (1995) Rediscovery of accessibility and economic potential: the critical issue of self-potential. Environ Plan A 27(11):1833-1848

Handy S, Niemeier D (1997) Measuring accessibility: an exploration of issues and alternatives. Environ Plan A 29(7):1175-1194

Hansen W (1959) How accessibility shapes land use. J Am Plan Inst 25(2):73-76

Kujala R, Weckström C, Mladenović M, Saramäki J (2018) Travel times and transfers in public transport: comprehensive accessibility analysis based on pareto-optimal journeys. Comput Environ Urban Syst 67:41-54

Kumar P, Parida M, Swami M (2013) Performance evaluation of multimodal transportation systems. Soc Behav Sci 104:795-804

Kwan M (1998) Space-time and integral measures of individual accessibility: a comparative analysis using a point-based framework. Geogr Anal 30(3):191-216

Langford M, Fry R, Higgs G (2012) Measuring transit system accessibility using a modified two-step floating catchment technique. Int J Geogr Inf Sci 26(2):193-214

Li S, Duan H, Smith T, Hu H (2021) Time-varying accessibility to senior centers by public transit in Philadelphia. Transp Res Part A Policy Pract 151:245-258. https://doi.org/10.1016/j.tra.2021. 06.020

Liu S, Yao E, Li B (2018) Exploring urban rail transit station-level ridership growth with network expansion. Transp Res Part D 73:1-12

Minal, RaviSekhar C (2016) Commuter's sensitivity in mode choice: an empirical study of New Delhi. J Transp Geogr 57:207-217

Moyano A, Moya-Gómez B, Gutiérrez J (2018) Access and egress times to high-speed rail stations: a spatiotemporal accessibility analysis. J Transp Geogr 73:84-93

O'Sullivan D, Morrison A, Shearer J (2000) Using desktop GIS for the investigation of accessibility by public transport: an isochrone approach. Int J Geogr Inf Sci 14(1):85-104

Prasertsubpakij D, Nitivattananon V (2012) Evaluating accessibility to Bangkok Metro Systems using multi-dimensional criteria across user groups. Int Assoc Traffic Saf Sci 36:56-65

PTEG (2010) Transport \& social inclusion: have we made the connections in our cities? PTEG Wellington House, Leeds

Raju SR, Wajid S, Radhakrishnan N, Mathew S (2020) Accessibility analysis for healthcare centers using gravity model and geospatial techniques. TeMA J Land Use Mobility Environ 13(1):6-20. https://doi.org/10.6092/1970-9870/6414

Roy S, Shah A (2018) The leap blog. Concerns with Delhi Metro, 14 December

Savigear F (1967) A quantitative measure of accessibility. Town Plan Rev 38(1):64-72

Shimbel A (1953) Structural parameters of communication networks. Bull Math Biophys 15(4):501-507

Straatemeier T (2008) How to plan for regional accessibility? Transp Policy 15(2):127-137

Wachs M, Kumagai T (1973) Physical accessibility as a socio-economic indicator. Socioecon Plan Sci 7(5):437-456

Wang Z, Chen H, Ou Y (2020) Research on regional traffic and economic linkage based on accessibility and gravity model-taking Hengyang, China as an example. In: 2020 4th International workshop on renewable energy and development (IWRED 2020). IOP Conference Series: Earth and Environmental Science, vol 510, pp 062005. https://doi.org/10.1088/1755-1315/510/6/062005

Xia N, Cheng L, Chen S, Wei X, Zong W, Li M (2018) Accessibility based on gravity-radiation model and google maps API: a case 
study in Australia. J Transp Geogr 72:178-190. https://doi.org/ 10.1016/j.jtrangeo.2018.09.009

Yang R, Liu Y, Liu Y, Liu H, Gan W (2019) Comprehensive public transport service accessibility index-a new approach based on degree centrality and gravity model. Sustainability 11:5634. https://doi.org/10.3390/su11205634
Yigitcanlar T, Sipe N, Evans R, Pitot M (2007) A GIS-based land use and public transport accessibility indexing model. Aust Plan 44(3):30-37 